\title{
Global public-private partnerships against neglected diseases: building governance structures for effective outcomes
}

\author{
SEBASTIAN BUCKUP* \\ Global Partnership Governance Initiative, Switzerland
}

\begin{abstract}
Focusing on the problem of pharmaceutical R\&D for drugs and vaccines against neglected diseases in developing countries, this article argues that the effectiveness of global health partnerships potentially lies in their capacity to address the problem of dual market failures: on a first level they may tackle the poverty induced lack of effective demand for health products which impedes the creation of market-financed innovative products. On a second level, they may help overcoming hold-up problems and underinvestment induced by the complexity of neglected diseases R\&D. Yet, organizing transactions within a partnership is not a panacea against these problems: a crucial determinant of success is proper ownership structures. They need to respond to (i) the degree to which the respective parties value the partnership outcome, (ii) the relative importance of the investment of the parties, and (iii) the nature of the partnership outcome. The argument developed in the analysis is built on an integrated framework combining insights from incomplete contracting theory and public goods economics. It is supported by a preliminary statistical analysis of 17 GHPs.
\end{abstract}

\section{Introduction}

\section{The emergence of global health partnerships}

Many diseases in Low and Middle Income Countries (LMICs) are being characterized by a lack of commercial incentives to trigger private investment in R\&D. Diseases such as Malaria, Tuberculosis, Chagas, and others, often affect millions of patients whose lack of ability to pay for market-financed products means there is still no market for drug developers to exploit. Because of that, they are also referred to as neglected diseases (NDs) (Nwaka and Ridley, 2003: 919). Since the mid-1990s a number of global health partnerships (GHP) between public and private actors have emerged to narrow this gap.

*Correspondence to: Sebastian Buckup, Project Manager, Global Partnership Governance Initiative, 20 Rue de la Filature, 1227 Carouge (Geneva), Switzerland. Email: s.buckup@alumni.lse.ac.uk 
Table 1. GHPs for drug and vaccine development

\begin{tabular}{ll}
\hline \hline Acronym & Name \\
\hline Aeras & Aeras, Global TB Vaccine Foundation \\
CDND & Consortium to Develop New Drugs \\
CICCR* & Consortium for Industrial Collaboration in Contraceptive Research \\
CONRAD & Contraceptive Research and Development Program \\
DVP* & Dengue Vaccine Project \\
DNDi & Drugs for Neglected Diseases Initiative \\
EMVI & European Malaria Vaccine Initiative \\
EuroVacc & EuroVacc Foundation \\
FIND & Foundation for Innovative New Diagnostics \\
TB Alliance & Global Alliance for TB Drug Development \\
HHVI & Human Hookworm Vaccine Initiative \\
IDRI & Infectious Disease Research Institute \\
IOWH & Institute for One World Health \\
IAVI & International AIDS Vaccine Initiative \\
IPM & International Partnership for Microbicides \\
LFI & Lassa Fever Initiative \\
MVI & Malaria Vaccine Initiative \\
MMV & Medicines for Malaria Venture \\
MVP & Meningitis Vaccine Project at WHO/PATH \\
PDVI & Pediatric Dengue Vaccine Initiative \\
\hline
\end{tabular}

Notes: "CICCR, DVP, and LFI have been left out of the analysis because of insufficient data.

Source: Initiative on Public-Private Partnerships for Health (IPPPH), http://www.ippph.org, July 13 2006.

The reasons for that have been traced back to both paradigm shifts in the development discourse and changes of interests in a globalizing world. ${ }^{1}$ Yet, looking ahead, it is of greatest importance to understand how sustainable these innovations are: are GHPs just a passing fad or are they here to stay as a fundamental pillar of governance in an emerging global public domain?

This paper argues that the answer to this question must flow from the conclusions reached about the effectiveness of the approach as a system of governance. It shows that GHPs as a form of organizational integration are effective when helping to overcome hold-up problems created through strategic behaviour of market actors in case of complex transactions, which make complete, contingent contracts infeasible. The argument developed in the analysis is built on an integrated framework combining insights from incomplete contracting theory and public goods economics. It is supported by a preliminary statistical analysis of 17 global partnerships for drug and vaccine development (see Table 1). The aim of the study is first to enhance the theoretical understanding

1 For paradigmatic explanations see e.g. Biersteker (1995), Jayasuriya (2001); Changes of interests particularly regarding global security threats have been extensively discussed by Kaul et al. (2003), Kaul and Conceição (2006), Kickbusch and Buse (2006), or Brundtland (2003). 
of the opportunities and limitations of public-private partnering as a system of governance. Secondly, it intends to lay the grounds for developing an analytical tool that helps decision makers to assess when partnering is preferable to other means of cooperation, and how GHP governance structures need to be designed to deliver effective outcomes.

\section{Public-private partnerships: just a fad?}

\section{Making a case for Global Health Partnerships}

Examining the still narrow literature on GHP governance reveals that the discussion is strongly biased towards issues of accountability and legitimacy rather than informing about determinants of effectiveness. ${ }^{2}$ Even though both aspects often go hand in hand, there are important differences: whereas effectiveness refers to the role institutions play as determinants of the content of individual and collective behaviour, legitimacy is concerned with normative concerns of fairness and equity (Young, 1992: 164). To be sure, the latter dimension needs to be addressed carefully and there is vast agreement that rules need to be established to increase the legitimacy of GHPs.

Yet, having said this, the normative spin of the governance debate overshadows the question what makes partnering a viable option for potential contributors at all: this, however, is an important question since partnering as a form of 'governance without government' is largely a voluntary mechanism of cooperation rather than a construction built on coercion. That means, the governing structures of GHPs do not only need to respond to - however defined normative considerations of equity and fairness but they also need to take into account the varying interests of the stakeholders to attract their voluntary contributions. Kettler and Towse (2001: 63) make this point clear: 'if the only issue is democratic legitimacy and [the] delivery [of outcomes] is assumed to be straightforward then the case for PPPs is weak'. Yet, as the authors go on, 'it is precisely because delivery is extremely difficult (and costly compared to the size of existing international agency budgets for this type of product development) that PPPs become an attractive option'.

Still, the comparative advantage of industry in the R\&D process is a strong argument for contracting out research and development to private corporations ('private sector participation') but not necessarily for partnering. Apart from that, also financial bottlenecks provide only an insufficient explanation for partnering since these supposedly could be overcome through alternative mechanisms such as Advanced Market Commitments, tax credits, lower regulatory

2 Particularly prominent is the concept of good governance in international organizations (see Woods, 1999). It provides the theoretical foundations in studies such as Buse (2004a, 2004b), Buse and Waxman (2001), Buse and Harmer (2004), Buse and Walt (2000a, 2000b, 2002a, 2002b), Kickbusch and Buse (2006). 
fees or fast-track approvals (Widdus, 2001: 716; Moran, 2005b: 16). These mechanisms have the advantage to keep the border between the public and the private clear, with the latter providing the institutional framework for the former to generate socially optimal results.

So, after all, does that suggest GHPs are no more than a passing fashion, questionable from both normative considerations of political legitimacy and also positive considerations of effectiveness? As the following sections argue, the answer is in the negative: one point of retreat for defenders of GHPs remains, and taking a closer look at it reveals its high relevance for many problems of global public policy making: in situations where the complexity of jointly produced outcomes is high, imperfect information lets the costs of market transactions rise and complete contracts covering all eventualities become infeasible. In the corporate world, such situations provide an important rationale for building alliances, joint ventures, mergers, and takeovers. Analogously, the problem of incomplete contracts also provides a strong rationale for global alliances between the public and the private sector.

As follows, the paper needs to address two questions: (i) what makes partnerships more effective than other systems of governance and when? (ii) How do global health partnerships need to be structured to create benefits for all stakeholders, so that they engage in voluntary cooperation?

\section{Theoretical framework: incomplete contracting}

Paradoxically, neoclassical economics does not know organizations: strictly speeking, it starts out from the idea of individuals interacting on spot markets. The reason for that is the assumption of perfectly informed actors and zero transaction costs. Thus, an important argument for the existence of organizations comes into view with the assumption of positive transaction costs: Coase suggests that transactions will be organized in a firm when the costs of doing so are below the costs of using the market (Coase, 1937). This can be the case when the good to be exchanged is complex, or when the contract spans a long time period, making it infeasible to specify all eventualities upfront. To give an example: suppose there is a buyer $G$ and a vendor $N$ of a good. Furthermore, suppose both need to make specific investments into the relationship: $N$, for instance, purchases a certain machine, whereas $G$ makes infrastructure investments adapted to the product delivered by $N$. Suppose both investments cannot be easily transferred to another purpose, i.e. they lose value in the case of disagreement. As a matter of consequence - even if beforehand both actors could chose between many providers - once the investments are sunk, there exists a certain degree of interdependence, giving each party some bargaining power over the other.

The bargaining power of both depends to large extend on their respective relative costs of exit, their disagreement payoff (see Hirschman, 1970: 21). The costs of exit of a party increase the more relationship specific investments 
it makes. If now the assumption is made that for each party the specific investments of the other are hard to observe, both anticipate the ex post bargaining over the surplus ex ante in their business negotiations (see Tirole, 1986). The result is an inefficient Nash equilibrium, i.e. individual strategic behaviour leads to hold-up problems and underinvestment (Besley and Ghatak, 2001: 1344).

Transaction cost theory suggests for such a situation of interdependence to organize the deal within one organization instead of using the market. This, however, potentially creates a new problem as Grossman and Hart (1986) make clear: suppose $G$ buys $N$, the former cannot be sure that $N$ does not turn from a self-interested owner to an equally self-interested employee (p. 692). In other words, integration merely 'shifts the incentives for opportunistic and distortionary behaviour; but it does not remove these incentives' (ibid.: 716).

This has two opposing consequences: on the one hand, G's incentive to make relationship-specific investments increases with the acquisition since it gives him residual control rights over the assets of $N$. On the other hand, integration diminishes incentives for $N$ to make relationship-specific investments since $N$ will now receive a smaller fraction of the ex post surplus.

Two conclusions can be drawn from the baseline model of incomplete contracting theory (as follows ICT): (i) The impossibility of making complete contracts in the case of complex transactions provide organizations with an incentive to integrate when their activities are complementary, i.e. when there is a certain degree of perceived interdependence between their investment decisions. (ii) The organization with relatively more important relationship-specific investments has a stronger incentive to gain residual control rights over the other because it potentially suffers more from a weaker bargaining position.

\section{GHPs as response to dual market failures}

The previous section laid the grounds for establishing a theoretical rationale for organizational integration as an alternative to market transactions: GHPs can be interpreted as a response to dual market failures:

1. At the first level extreme poverty leads to lack of effective demand for the creation of market-financed innovative products for health. This has been exacerbated by important dynamics of economic globalization in the pharmaceutical industry: since the 1980s the branch saw the emergence of 'big pharma', a surge of global mergers and acquisitions which let the business to consolidate from formerly 25 down to 15 big players with more than US $\$ 10 \mathrm{bn}$. healthcare revenue each in 2004. ${ }^{3}$ This development has driven these companies to focus on areas offering ever-higher returns, which let the typical peak sales threshold for drug R\&D candidates increase around US \$500 millions per year. 
As a consequence, the project selection process in companies got more competitive, and opportunity costs associated with investment in ND R\&D rose. Companies such as Roche, Bristol-Myers Squibb, Abbott, Lilly, or Wyeth entirely closed down their infectious diseases divisions (Moran, 2005b: 9; Buse and Walt, 2000a: 552; Tarabusi and Vickery, 1998a, 1998b).

2. Not only the demand side but also the supply side suffers from potential market failures: pharmaceutical research is a highly complex endeavour and requires project specific investments, which are difficult to observe, understand, or verify for the recipient of the good. Not only the private but also the public sector needs to make investments throughout the different stages of the R\&D process, e.g. in terms of technical, scientific, and clinical neglected disease expertise; access to facilities pharmaceutical corporations no longer have (e.g. parasite houses, developing country trial sites); or regional experience (e.g. dealing with developing country health authorities) (Moran, 2005b: 13). Thus, all parties make financial, human, and physical contributions to the common project according to their respective comparative advantage. The complementarity of the inputs and the complexity of the production process give rise to contracting problems in a situation of complex interdependence. Since this is prone to result in opportunistic and inefficient strategic behaviour, there is a need for organizational integration.

\section{Effective governance structures}

\section{An incomplete contracting approach}

So far, the analysis allows for an explanation of why R\&D partnerships can be potentially superior to market transactions. Yet, as the theory suggests above, integration per sé is not enough to solve hold-up problems and improving overall effectiveness: it is decisive who has the residual rights over the assets brought into the partnerships, i.e. who owns the GHP. So, the question is: what ownership structures provide effective outcomes under what circumstances? Answering this question requires the assumptions of the ICT baseline model to be modified in two respects: (i) the product of the partnership has (to large extent) a public rather than private good character; (ii) the actors value the outcome of the partnership to different degrees, with the private for-profit actor, in the extreme case, not valuing it at all.

\section{Public sector versus non-government organizations' (NGO) ownership}

of partnerships - the theory

Roughly, the life of a GHP can be described as a three-stage process: (1) In the formation negotiations, the parties decide over setting up the partnership. They have to agree over the objectives of the research, how the project will be managed, and over the obligations of each party. A central subject of these negotiations is the representation of stakeholders in the Governing Board that is the 
owner of the assets brought into the partnership (i.e. it has residual control rights over the assets contributed by the donors). (II) The Governing Board and the CEO decide over the investments that are henceforth to be sunk (relationship specific). (III) After a normally predetermined project phase, the stakeholders evaluate the outcomes and bargain over whether to continue the project and with whom.

As the theoretical framework suggests, the formation of a partnership per sé is not yet a solution to the problem of incomplete contracting: once the actors have arrived in phase II, they will - analogously to the corporate case - still be in a situation of interdependence, which potentially leads to hold-up problems. To avoid this, a proper governance structure is crucial: in the corporate case, the proposition is that the stakeholder with the relatively more important investment is the one facing higher costs of exit once the investment is sunk. This puts them in a weaker ex post bargaining situation, so that they would invest more if they became the owner of the project (which would improve their bargaining position). Yet, in an organization which produces a public good, the situation is different because the residual control (i.e. ownership) over the assets contributed to the venture and the residual income derived from these assets are largely decoupled: when the output of a partnership is a public good, the party which values this good the most derives the largest benefits no matter who is the owner. In other words, ownership does not implicate a better bargaining position since the party valuing the outcome more also benefits more whether or not it is directly involved! This has an important implication for the less caring investor: their bargaining position now improves when they transfer ownership rights to the higher valuation party, supposing the latter cannot complete the project without them. This leads to an important conclusion: the investments of the less caring party are higher when they are not the owner of the project. In contrast to the baseline model, the overall surplus is always higher when the more caring party retains ownership (see Besley and Ghatak, 2001: 1353).

Strictly speeking, the analysis up to this point only provides propositions in the extreme case (total public versus total NGO ownership). Yet, when is joint ownership preferable? A simple example illustrates: if a conflict arises in a twostakeholder partnership where ownership rights are with stakeholder $G$ who decides to dismiss $N$, the latter would still earn a positive residual income from the partnership since it is public. In case of joint ownership, however, which means in the most extreme case that every Board Member is a veto power, the project cannot go on when there is disagreement, so that the disagreement payoffs are zero. Thus, in practice joint ownership means that the relatively less caring party achieves an even better bargaining position than in the case above, which potentially improves its investment incentives. Such a setting is preferable when the success of the partnership depends largely on, or even entirely on, the investment of the less caring party (Besley and Ghatak, 2001: 1356). This is particularly the 
Figure 1. Public versus non-profit private ownership of a GHP

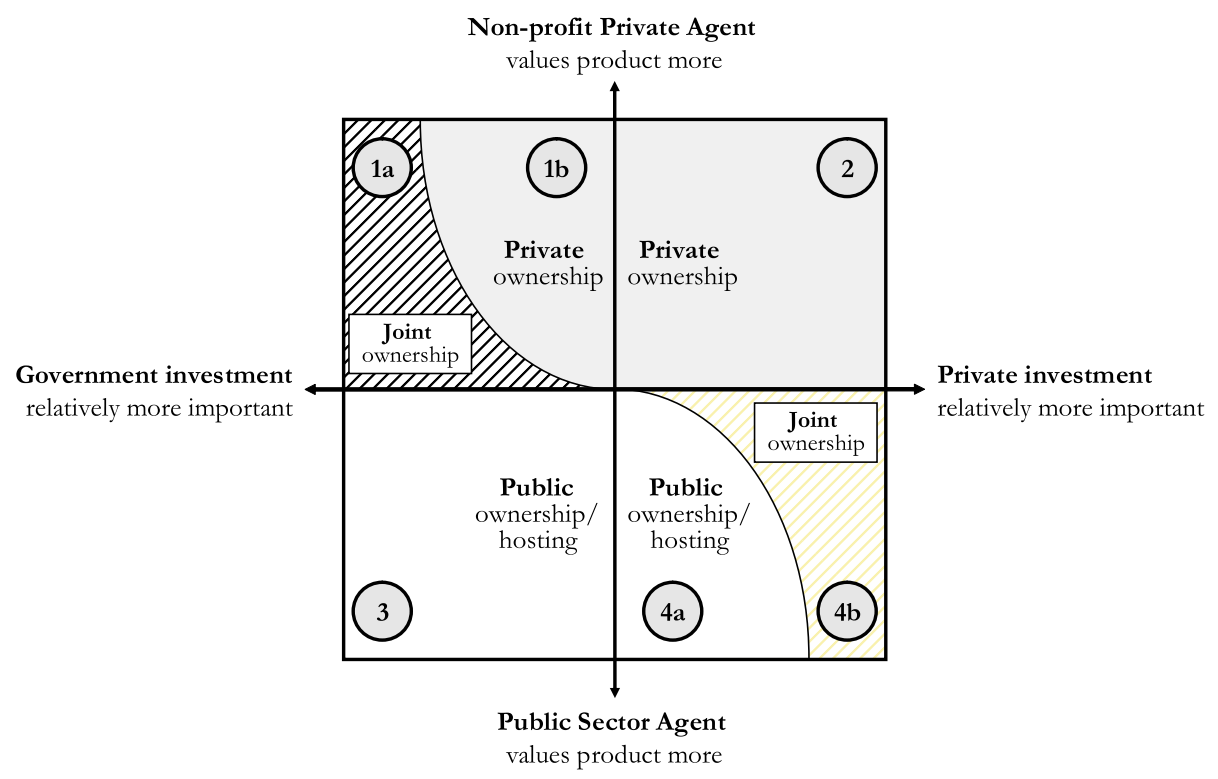

case when there is a wealth constraint for the other stakeholders, meaning it is impossible for them to go on without the investment of the less caring party: a typical scenario in neglected diseases R\&D.

The propositions the ICT perspective yields are illustrated in Figure 1, which distinguishes between public sector agents and non-profit private agents. The former group of actors consists of national development agencies (e.g. DFID, USAID), public research institutions and universities, and multilateral bodies (e.g. UNAIDS, WHO). The group of non-profit private agents encompasses NGOs and philanthropic funds (e.g. Rockefeller Foundation, Bill and Melinda Gates foundation).

The figure suggests that when the most caring party is also contributing the relatively more important investment to the partnership, it should own the project (quadrants 2 and 3). It furthermore suggests that the more caring party should be the owner even if the other party invests relatively more (quadrants $1 \mathrm{~b}$ and $4 \mathrm{a}$ ). Only if there were a large gap between valuation and funding would there be a case for joint ownership (quadrants $1 \mathrm{a}$ and $4 \mathrm{~b}$ ).

\section{Public versus NGO ownership of partnerships - the evidence}

The theoretical deliberations above yield the following concluding proposition: in the public goods case the effectiveness of a partnership is greater when the higher valuation party owns the project no matter who is the investor, given that there is no major wealth constraint. Otherwise, there is a case for joint ownership. 
The raw data for the following analysis are collected from official statements of GHPs, as well as from the IPPPH partnership database ${ }^{4}$ (see Annex: Table A1). They show 17 out of 20 R\&D GHPs presently operating. ${ }^{5}$ Table 2 draws on these data to calculate differences among these partnerships with regard to voting power in the governing bodies and financial contributions.

The variable $\% P U B$ in Table 2 is the share of the total investment in the GHP contributed by public stakeholders. As the table shows, almost all investments, i.e. $\% F U N(=1-\% P U B)$, comes from private funds, rather than from corporate investors (Figure 2). Overall, the data suggest that there is a clear trend in the field of ND research towards the establishment of jointly owned GHPs. Another indicator for this is the fact that GHPs increasingly take the form of legally independent organizations or organizations hosted within NGOs. Publicly owned partnerships, on the other hand, gradually lose importance (see Table 3; nine of 13 so far discontinued partnerships have been hosted by the public sector).

The parameter \%INO ('investor ownership') in Table 2 describes the share of votes held by all investors: comparing this parameter with \%PUB shows no correlation.

An even clearer picture emerges when disaggregating $\%$ INO into two variables: \%PRD ('private donor ownership') describes the percentage of votes going to private funds, whereas \%PUD ('public donor ownership') describes the votes held by donor countries and multilateral donor agencies. Comparing the contributions of private funds (\%FUN) with their ownership share $(\% P R D)$ shows no correlation (Table 4$)$ : compared to their investment they always have very little influence in the GHP. This confirms the main proposition of the ICT perspective on GHPs: investment and ownership are in the public good case not necessarily correlated.

Interestingly, as Table 4 illustrates, comparing the contributions of public donors $(\% P U B)$ and their voice in the GHP $(\% P U D)$ shows that they remain correlated: a larger investment usually results in stronger representation. A possible interpretation is that governments invest more in partnerships that serve their own interest. In fact, there may be some evidence for that interpretation, when baring in mind that the literature usually differentiates between two distinct driving forces behind global health partnering: (a) the acknowledgement that good health in LMICs constitutes a value in itself and is a prerequisite for economic development, and (b) the perception that NDs in LMICs may become a threat for HICs per sé. It can be assumed that the latter concern applies less to diseases that are bound to certain geographical or climatic areas

4 www.ippph.org.

5 The partnerships which have been left out (CICCR, DVP, and LFI) did not provide sufficient information. 
Table A1. Distribution of ownership and investment in R\&D GHPs

\begin{tabular}{|c|c|c|c|c|c|c|c|c|c|c|c|c|c|c|c|}
\hline \multirow[t]{3}{*}{ Name* } & \multirow[t]{3}{*}{ LS } & \multirow[t]{3}{*}{ Diseases* * } & \multicolumn{5}{|c|}{ Finance (Mill. US\$) } & \multicolumn{8}{|c|}{ Ownership (Board Votes) } \\
\hline & & & \multirow{2}{*}{$\begin{array}{l}\text { Public } \\
\text { Gov/Mu. }\end{array}$} & \multicolumn{2}{|c|}{ Private } & \multirow{2}{*}{$\begin{array}{l}\text { Total } \\
\text { Invest }\end{array}$} & \multirow[t]{2}{*}{$\%$ Pub } & \multicolumn{3}{|c|}{ Public } & \multicolumn{4}{|c|}{ Private } & \multirow{2}{*}{$\begin{array}{l}\text { Total } \\
\text { Board }\end{array}$} \\
\hline & & & & Funds & Corp. & & & Gov/Mu. & Other & $\% \mathrm{DEC}$ & Funds & Exp. & Corp. & $\%$ DEC & \\
\hline Aeras & IND & $\mathrm{TB}$ & 4.47 & 107.90 & 0.00 & 112.37 & $4 \%$ & 0 & 3 & $33 \%$ & 1 & 4 & 2 & $0 \%$ & 10 \\
\hline CDND & PS & LEI, MAL, HAT & 2.20 & 15.10 & 0.00 & 17.30 & $13 \%$ & 0 & 3 & $0 \%$ & 1 & 0 & 0 & $0 \%$ & 4 \\
\hline CONRAD & $\mathrm{NP}$ & HIV/AIDS & 72.00 & 50.41 & 0.00 & 122.41 & $59 \%$ & 3 & 0 & $0 \%$ & 0 & 2 & 0 & $50 \%$ & 5 \\
\hline DNDi & IND & CD, LEI, MAL, HAT & 0.47 & 32.50 & 0.00 & 32.97 & $1 \%$ & 5 & 0 & $80 \%$ & 1 & 3 & 0 & $0 \%$ & 9 \\
\hline EMVI & NP & MAL & 8.50 & 0.00 & 0.00 & 8.50 & $100 \%$ & 6 & 1 & $14 \%$ & 0 & 0 & 1 & $0 \%$ & 8 \\
\hline EuroVacc & IND & HIV/AIDS & 2.80 & 0.00 & 0.00 & 2.80 & $100 \%$ & 0 & 6 & $0 \%$ & 0 & 0 & 2 & $0 \%$ & 8 \\
\hline FIND & IND & $\mathrm{TB}$ & 0.00 & 30.00 & 0.00 & 30.00 & $0 \%$ & 1 & 0 & $100 \%$ & 1 & 1 & 1 & $0 \%$ & 4 \\
\hline HHVI & NP & $\mathrm{HHI}$ & 0.00 & 39.80 & 0.00 & 39.80 & $0 \%$ & 0 & 1 & $100 \%$ & 0 & 5 & 0 & $20 \%$ & 6 \\
\hline IAVI & IND & HIV/AIDS & 112.69 & 151.60 & 0.00 & 264.29 & $43 \%$ & 5 & 0 & $60 \%$ & 0 & 4 & 4 & $13 \%$ & 13 \\
\hline IDRI & IND & CD, LEI, LEP, MAL, TB & 0.00 & 15.00 & 0.00 & 15.00 & $0 \%$ & 0 & 4 & $0 \%$ & 0 & 4 & 0 & $0 \%$ & 8 \\
\hline IOWH & IND & CD, LEI, LEP, MAL, DIA & 0.00 & 62.96 & 0.00 & 62.96 & $0 \%$ & 0 & 0 & $0 \%$ & 2 & 3 & 3 & $0 \%$ & 8 \\
\hline IPM & IND & HIV/AIDS & 19.42 & 75.15 & 0.00 & 94.58 & $21 \%$ & 2 & 2 & $50 \%$ & 0 & 5 & 3 & $13 \%$ & 12 \\
\hline MMV & IND & MAL & 40.74 & 193.82 & 1.30 & 235.85 & $17 \%$ & 3 & 0 & $33 \%$ & 1 & 7 & 1 & $22 \%$ & 12 \\
\hline MVI & NP & MAL & 0.00 & 257.60 & 0.50 & 258.10 & $0 \%$ & 2 & 2 & $75 \%$ & 0 & 4 & 2 & $17 \%$ & 10 \\
\hline MVP & NP & MEN & 0.00 & 70.00 & 0.00 & 70.00 & $0 \%$ & 2 & 2 & $75 \%$ & 0 & 4 & 2 & $17 \%$ & 10 \\
\hline PDVI & PS & DEN & 0.00 & 56.08 & 0.00 & 56.08 & $0 \%$ & 8 & 6 & $71 \%$ & 0 & 9 & 2 & $9 \%$ & 25 \\
\hline TB Alliance & IND & $\mathrm{TB}$ & 2.00 & 40.15 & 0.00 & 42.15 & $5 \%$ & 1 & 3 & $0 \%$ & 1 & 3 & 3 & $17 \%$ & 11 \\
\hline
\end{tabular}

Notes: " see Table 1 for full names.

Global Security Threats: HIV = HIV/AIDS; MAL = Malaria; TB = Tuberculosis; Regional Development Threat: CD = Chagas; DEN = Dengue; DIA = Diarrhoeal Dis.; HAT = Human African Trypanosomiasis; HHI = Human Hookworm Infection; LEI = Leishmaniasis; LEP = Leprosy; MEN = Meningitis; ROT $=$ Rotavirus

Legend: $\quad$ Gov/Mu. = Governments \& Multilateral Organizations; Funds = Private Philanthropic Foundations; Corp. = For-Profit Private Actor; \% Pub = Public Sector share of overall investments; $\% D E C=$ share of Disease Endemic Countries; Exp. = Health Experts (Private Board Members which do not contribute funds). Source: Initiative on Public-Private Partnerships for Health (IPPPH), http://www.ippph.org, July 13. 
Table 2. Investments, voting power and project valuation

\begin{tabular}{|c|c|c|c|c|c|c|c|c|}
\hline Name* & Partnership Focus & $\%$ PUB & $\% F U N$ & $\%$ INO & $\%$ PRD & $\%$ PUD & $\%$ PUO & $\% \mathrm{COR}$ \\
\hline Aeras & Global Security Threat & $4 \%$ & $96 \%$ & $30 \%$ & $10 \%$ & $20 \%$ & $30 \%$ & $20 \%$ \\
\hline CONRAD & Global Security Threat & $59 \%$ & $41 \%$ & $60 \%$ & $0 \%$ & $60 \%$ & $60 \%$ & $0 \%$ \\
\hline EMVI & Global Security Threat & $100 \%$ & $0 \%$ & $75 \%$ & $0 \%$ & $75 \%$ & $88 \%$ & $13 \%$ \\
\hline EuroVacc & Global Security Threat & $100 \%$ & $0 \%$ & $75 \%$ & $0 \%$ & $75 \%$ & $75 \%$ & $25 \%$ \\
\hline FIND & Global Security Threat & $0 \%$ & $100 \%$ & $25 \%$ & $25 \%$ & $0 \%$ & $25 \%$ & $25 \%$ \\
\hline IAVI & Global Security Threat & $43 \%$ & $57 \%$ & $15 \%$ & $0 \%$ & $15 \%$ & $38 \%$ & $31 \%$ \\
\hline IPM & Global Security Threat & $21 \%$ & $79 \%$ & $17 \%$ & $0 \%$ & $17 \%$ & $33 \%$ & $25 \%$ \\
\hline MMV & Global Security Threat & $17 \%$ & $83 \%$ & $25 \%$ & $8 \%$ & $17 \%$ & $25 \%$ & $8 \%$ \\
\hline MVI & Global Security Threat & $0 \%$ & $100 \%$ & $10 \%$ & $0 \%$ & $10 \%$ & $40 \%$ & $20 \%$ \\
\hline TB Alliance & Global Security Threat & $5 \%$ & $95 \%$ & $45 \%$ & $9 \%$ & $40 \%$ & $40 \%$ & $27 \%$ \\
\hline CDND & Regional Development Threat & $13 \%$ & $87 \%$ & $100 \%$ & $25 \%$ & $75 \%$ & $75 \%$ & $0 \%$ \\
\hline DNDi & Regional Development Threat & $1 \%$ & $99 \%$ & $22 \%$ & $11 \%$ & $11 \%$ & $56 \%$ & $0 \%$ \\
\hline HHVI & Regional Development Threat & $0 \%$ & $100 \%$ & $0 \%$ & $0 \%$ & $0 \%$ & $17 \%$ & $0 \%$ \\
\hline IDRI & Regional Development Threat & $0 \%$ & $100 \%$ & $50 \%$ & $0 \%$ & $50 \%$ & $50 \%$ & $0 \%$ \\
\hline IOWH & Regional Development Threat & $0 \%$ & $100 \%$ & $25 \%$ & $25 \%$ & $0 \%$ & $0 \%$ & $38 \%$ \\
\hline MVP & Regional Development Threat & $0 \%$ & $100 \%$ & $10 \%$ & $0 \%$ & $10 \%$ & $40 \%$ & $20 \%$ \\
\hline PDVI & Regional Development Threat & $0 \%$ & $100 \%$ & $16 \%$ & $0 \%$ & $16 \%$ & $56 \%$ & $8 \%$ \\
\hline
\end{tabular}

\section{Notes:}

$\% P R D=($ Private Donor Votes $/$ Boards Size $) * 100 \quad \% P U B=($ Public Inv. $/$ Total Inv. $) * 100$

$\% P U D=($ Public Donor Votes $/$ Boards Size $) * 100 \quad \%$ FUN $=($ Private Inv. / Total Inv. $) * 100$

$\% P U O=($ All Public Votes $/$ Board Size $) * 100 \quad \% I N O=($ All Donor Votes $/$ Board Size $) * 100$

Source: Table A1

Figure 2. Financial contributions to R\&D GHPs (in \%)

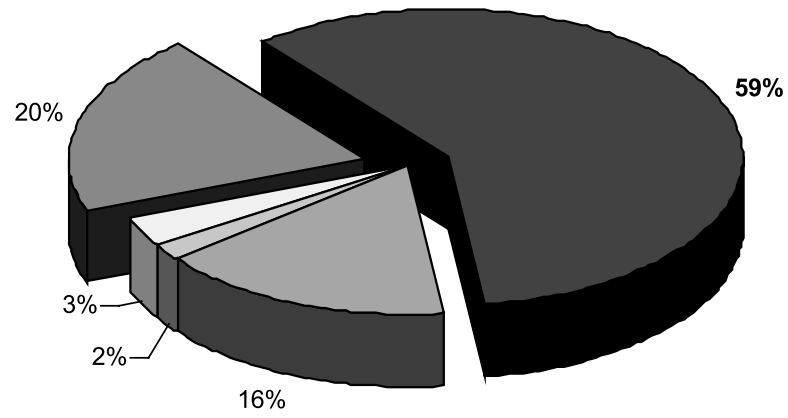

\section{$\square$ Public Sector \\ $\square$ UN Agencies}

$\square$ Other Philanthropic Foundations

- Gates Foundation

$\square$ For-Profit Private Sector

Source: Moran, 2005a: 33 
Table 3. Discontinued R\&D GHPs

\begin{tabular}{ll}
\hline \hline Name & End date \\
\hline Action TB Programme (ATBP) & 2003 \\
Development of Norplant & n.a. \\
Development of Vaccine Vial Monitors (VVMs) & n.a. \\
Intercompany Collaboration for AIDS Drug Development (ICCADD) & 2003 \\
Japanese WHO Malaria Drug Partnership (JPMW) & 2004 \\
Lapdap Antimalarial Product Development (LAPDAP) & 2004 \\
Meningitis C Vaccine Development and Supply in UK & 2003 \\
Microbicides Development Programme (MDP) & 2006 \\
Syringes - Autodestruct Development & n.a. \\
TROPIVAL & n.a. \\
Tuberculosis Diagnostics Initiative (TBDI) & n.a. \\
\hline \hline
\end{tabular}

Source: Initiative on Public-Private Partnerships for Health (IPPPH), http://www.ippph.org, 13 July 2006.

Table 4. Correlations: investments and project ownership

$\%$ PUB (Public Investment Share)

$\begin{array}{lc}\text { \% INO (Overall Investor Ownership) } & 0.457 * \\ \% \text { PUO (Overall Public Ownership) } & 0.517 * \\ \% \text { PRD (Private Investor Ownership) } & -0.247 \\ \% \text { PUD (Public Investor Ownership) } & 0.526 * \\ \% \text { COR (Corporate Investor Ownership) } & 0.020\end{array}$

Note: * Correlation is significant at the 0.05 level (2-tailed).

Source: Table 2 .

or affect only relatively few people ('Regional Development Threats'). Thus, from an ICT perspective, it is more likely that philanthropic funds invest into the fight against Regional Development Threats, whereas public donors focus more on major epidemics, which are not geographically bound or potentially dangerous for a large number of people, including those from developed countries (e.g. tourists traveling in malaria-risk areas). Furthermore, it is fair to assume that in the case of Regional Development Threats, NGOs and local governments are the most caring parties and have a larger share of the votes.

Table 2 provides some preliminary evidence that these assumptions hold true: it suggests that HIV/AIDS, Malaria, and TB are major epidemics which constitute a 'Global Security Threat'. Diseases like Chagas, Dengue, or Leishmaniasis are mostly health threats connected to local conditions non-existent in HICs. Obviously public donors play only a minor role in contributing financially to R\&D for the latter (see Figure 3). Also, the assumptions regarding ownership are supported by the evidence: in the four most important GHPs against regional threats, i.e. DNDi, IOWH, MVP, and PDVI, public donors 
Figure 3. Public investment, public ownership, and disease type

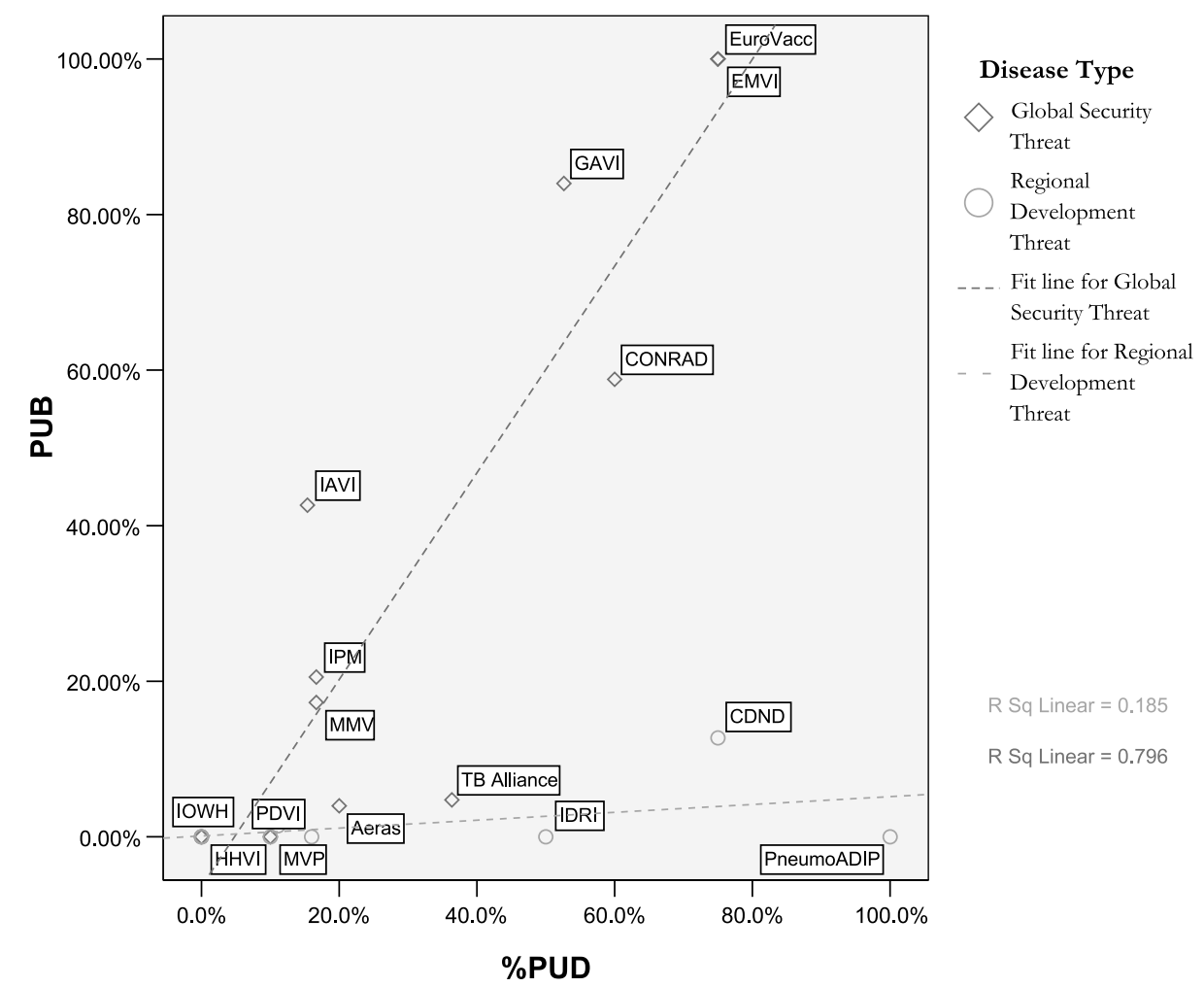

Source: Table 2.

have no significant ownership. Furthermore, with the exception of IOWH, these GHPs transferred significant ownership rights to Disease Endemic Countries (DEC) governments (this conclusion can be derived from calculating the difference between \%PUD and \%PUO: the former describes donor country ownership, the latter refers to overall public ownership, including DEC).

\section{Non-profit versus for-profit stakeholder ownership}

So far, the discussion focused on the trade-off between public and non-profit private ownership of GHPs. Now, to round up the ICT perspective on GHP governance, the corporate sector needs to be recognized. The key assumption made is that business gets no intrinsic value from the project. That means, since implementing a project is costly the company would not complete it in case of disagreement: it engages in the project only because of the payments it receives from the non-profit agent.

This brings the analysis back to the baseline ICT model. If the private sector, say a pharmaceutical company, receives ownership over an ND drug project, 
it has two options: (a) increasing relationship-specific investments and then negotiating with the purchaser to pay a higher price; (b) decreasing relationshipspecific investments and delivering a poorer product. When (a) is difficult to accomplish, adverse consequences of (non-contractible) cost cutting on (noncontractible) quality of the delivered product potentially occurs once ownership rights are transferred to the private company. The greater the danger of this opportunistic behaviour, the greater becomes the case for public ownership instead of transferring residual control rights to the company (Hart et al., 1997: 1130). So, if large non-contractible cost reductions have large deleterious consequences for the effectiveness of the GHP, the case for private ownership is small. If opportunistic behaviour can be controlled for through contract or competition (e.g. if the good has a private good component), there is a stronger case for private ownership since then such an arrangement potentially increases efficiency through cost reductions and/or quality innovations. Against the background that ND research is a complex process and assuming that pharmaceutical companies are profit-maximizing actors, the case for industry ownership seems small. However, two qualifications can be made to this 'first guess':

1. In the ND R\&D case corporate stakeholders often make in-kind contributions (e.g. laboratory access, general technological expertise), rather than financial contributions. So, no matter if they formally own the project or not, they retain residual control rights over these assets in case of disagreement, which improves their bargaining position. This is particularly the case if the assets contributed are not relationship specific, i.e. they may be transferred easily to other purposes. Thus, the degree of corporate ownership can be assumed to increase if its investment is sufficiently more important and/or less relationship specific.

2. There are production processes with a 'double bottom line', yielding both a public and a private good component. This, for instance, may be the case when a drug is agreed to be used for commercialization in HICs whilst being provided at low cost in LMICs. This creates incentives for joint ownership: suppose a private actor $P$ has an investment project but does not want to finance it himself since he would then bear the whole risk. When the project has a double bottom line, $P$ has an incentive to take in a non-profit investor $J$ who is less risk averse. $J$ is offered as payoff a sizable fraction of the project's benefit (the fraction that $J$ later intents to make public). Then, in order to prevent $P$ from withholding this ex post, $J$ would ask $P$ in advance to hand over some control, for example by giving him ownership rights over some of the assets (see Grossman and Hart, 1986: 717). Particularly, large charitable foundations increasingly fancy such an approach, giving rise to a new form of philanthrocapitalism, or 'venture philanthropy' (Economist, 2006).

Figure 4 illustrates the argument: if a product is a private good and the corporation is the sole investor, it would own the project (quadrant 2). If the good is public and the investment is not for profit, the project would be owned either 
Figure 4. Not-for-profit (public and private) versus corporate ownership

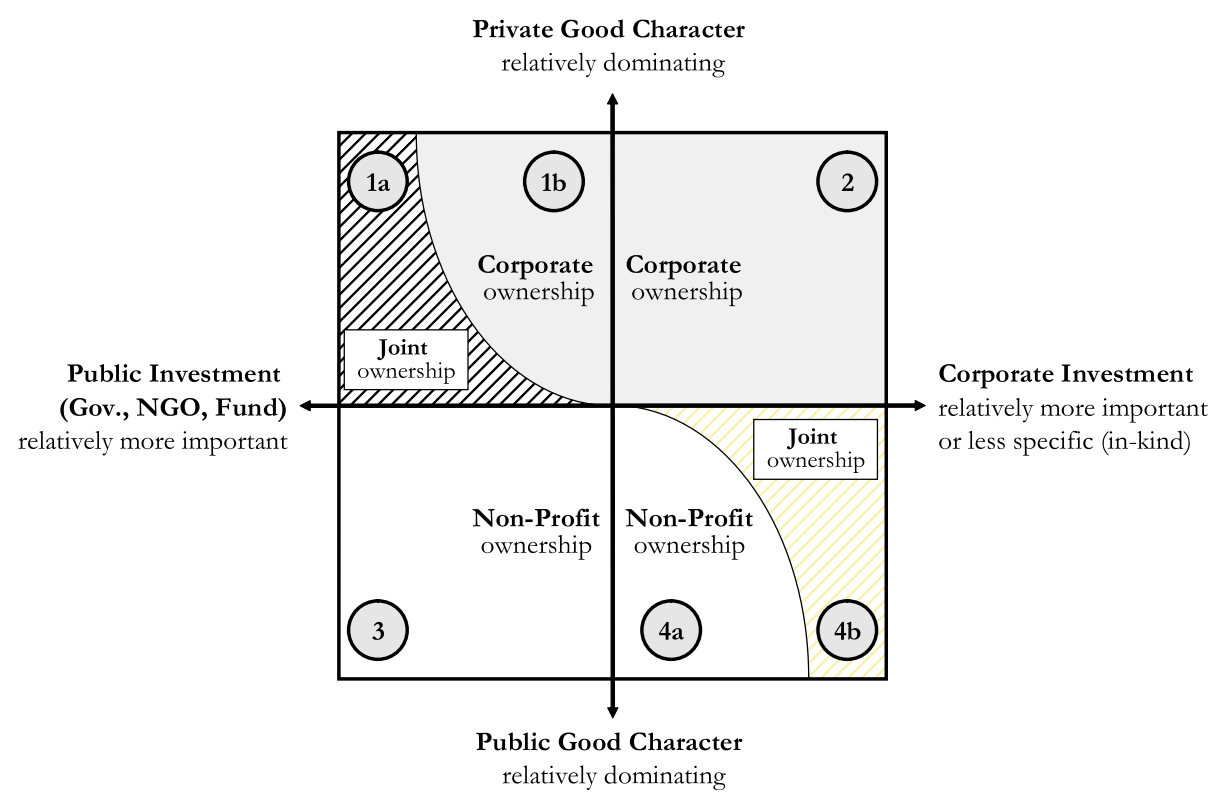

by the public sector or by a private not-for-profit actor, depending on the criteria above (quadrant 3). Double bottom line ventures would be either owned entirely by the corporation (quadrant $1 \mathrm{~b}$ ) when public contributions are small (e.g. tax credits) or are jointly owned as in the case of projects financed through 'venture philanthropic' investment (quadrant 1a). If the project outcome is public but a share of the investment is corporate, the project would still be owned by the public agent (quadrant 4a), unlike the investment of the for-profit stakeholder is sufficiently more important or less relationship specific (quadrant 4b).

Non-profit versus for-profit stakeholder ownership - the evidence

The deliberations above yield the following propositions: the effectiveness of a partnership between the for-profit and the non-profit sector is greater when the latter retains ownership unlike when (a) the good has a sizable private good component or (b) the investment of the for-profit stakeholder is sufficiently more important and/or less relationship specific. In the latter situations, there is a case for joint ownership.

As Table 2 shows, it is striking that \%COR ('corporate ownership') is positive for 12 out of 17 GHPs. That means corporations have a voice in most GHPs, albeit they do not tend to make financial contributions. Yet, in all observed cases, the voice of corporate stakeholders is minor compared to the voice of public actors. Furthermore, the Board members with the background 
of a for-profit organization are not necessarily from the companies that are involved in the R\&D activity of the partnership.

A closer look at industry partners shows that various factors determine the private sector's motives to invest in GHPs and to secure (or not to secure) ownership rights. The motives vary between Multinational Corporations (MNCs) and Small and Medium sized Companies (SMCs).

For MNCs, there are two major rationales to investing in an R\&D partnership: (1) the partnership generates private good components, which the MNC may appropriate and commercialize. This is either the case if the partnership yields products or product components that can also be sold in more attractive markets (e.g. HIV/AIDS treatments), or if an incentive regime has been set up to make the project profitable. The 1983 US Orphan Drug Act, for instance, makes firms that develop drugs for rare diseases eligible for a $50 \%$ tax credit on their clinical development expenses, provides clinical research grants, ensures priority review and fast track development status, and guarantees a seven-year market exclusivity period. A more recent incentive mechanism is Advance Market Commitments (AMC), which create a guaranteed demand for a drug, or vaccine before it is on the market. In February 2007, a pilot AMC has been set up by the Bill and Melinda Gates Foundation and five donour countries to spur the development of a vaccine against Pneumococcal disease.

(2) MNC investments into R\&D partnerships can also have non-commercial reasons or may be linked to long-term business considerations. These include strategies to improve the corporate image and the prevention of risks to reputation, which may result from a failure to address developing country needs (Buse and Walt, 2002b: 175). They may also include an early positioning in emerging LMIC markets or access to high-skilled low-cost developing country researchers. Moran (2005b: 17) stresses that in the realm of drug development such motives currently provide the dominant driver for MNCs to contribute to GHPs.

The varying motives for large pharmaceutical companies to participate in a GHP also determine ownership structures. When, as in the first setting, the $\mathrm{R} \& \mathrm{D}$ project is supposed to yield an immediate profit for the MNC, there is a strong case for private ownership. The pneumococcal vaccine PREVANAR, for instance, has been developed by the pharma company Wyeth on a commercial basis and was incorporated into various childhood immunization programs around the world. In the context of the recent launch of an AMC for pneumococcal vaccines, the company announced the development of an advanced pneumococcal vaccine with a broader coverage.

The case for joint ownership of MNCs in GHPs increases with the importance of the contribution of the public sector to the venture. Table 2 provides some evidence that the degree of MNC ownership is larger in partnerships like IAVI, which are tackling global security threats, than in others, which are tackling local development threats. Arguably, this can be linked to larger private good components in the former. 
When, as in the second case, the R\&D project itself is not supposed to yield an immediate profit, MNCs prefer to share the burden of the investment in what is called a 'no-profit-no-loss' model: they provide early pipeline R\&D, which is relatively cheap and relationship unspecific, and leave the relatively expensive late-stage clinical development to the public partner (Moran, 2005b). In such a setting, ownership usually stays with the latter. GSK, for instance, is involved in various early stage Malaria and TB projects with MMV and the TB Alliance, without being represented on the organizations' Boards. Also, Novartis is involved in partnerships with both GHPs without being represented on their respective Boards. Sanofi-Aventis collaborates with DNDi without having formal project ownership rights. The case for joint ownership would only grow if the contribution of the MNC was sufficiently important. In the set of GHPs examined by this paper, this has not been the case.

Whereas MNCs do not necessarily need to draw an immediate commercial benefit from their ND research, SMCs tend to work on a fully paid basis. Around half of today's neglected disease drug projects are conducted with the contribution of SMCs (Moran, 2005b). Some of these are Contract Research Organizations (CROs) such as Quintiles or Covance, which produce research on demand. Since tasks outsourced to CROs can usually be clearly defined and measured, they collaborate on a transactional basis and do not obtain ownership rights.

A second group is SMCs, which specialize on the niche market of ND product development (e.g. Zentaris, Immtech). Their key driver is the expectation of profits from sales of the final product to the ND market itself. Cooperations with these companies fit into quadrant $1 \mathrm{a}, \mathrm{b}$, or quadrant 2 of Figure 4, depending on to what degree they trade residual rights over their assets against contributions of the non-profit partners. Among the partnerships outlined in Table 2, the Institute for One World Health $(\mathrm{IOWH})$ belongs to this still rather small group of SMCs specializing in neglected disease markets.

\section{Conclusion}

\section{Policy implications and research agenda}

This paper started out from the assertion that due to the normative bias of the debate on GHP governance one fact is usually vastly ignored: GHPs are voluntary systems of cooperation and hence need to yield benefits to all participating parties to be effective. Because of that, this paper suggested a new perspective on GHP governance based on incomplete contracting theory. The purpose of this was to answer the questions why GHPs are potentially more effective than market-based transactions between public and private agents, and what the positive criteria are that their governance structures need to correspond to. 
The answer offered to the first question is that GHPs may overcome critical hold-up problems emerging through inefficient strategic behaviour of market actors when the complexity of a transaction makes complete, contingent contracts infeasible. Yet, as the theory shows as well, this transaction costs argument needs to be qualified, since organizational integration also produces adverse incentives for the partners. Because of that, the paper suggests that systematically weighting the benefits of integration against its harms in terms of adverse incentives must be the key to solving the second puzzle regarding positive criteria of governance. Several propositions could be derived this way: the distribution of ownership rights in a GHP needs to correspond to: (i) the degree to which the respective parties value the partnership outcome, (ii) to the relative importance of the investment of the parties, and (iii) the nature of the partnership outcome produced. The empirical sections of the paper were able to support the theoretical ICT assumption on GHP governance.

It is important to point out that the empirical findings provided are not sufficient yet to establish an immediate causal relation between certain forms of governance and partnership effectiveness. Yet, they are clear enough to give the GHP governance debate a new spin by informing it about which constellations (ownership structures) are potentially more effective under which circumstances (nature of the good, wealth constraints of the actors, etc.) and which potentially fail. However, to be sure, the findings in this paper can complement but not replace a sophisticated normative debate on the consequences of public-private partnering: the ICT framework may explain why and under what circumstances a multilateral organization needs to trade some voting power against private contributions. It remains necessarily silent on the question of whether these circumstances per sé are desirable.

Finally, it is necessary to discuss the explanatory power of the model as such, as well as the empirical examination provided in the analysis. To begin with the former, it is important to point out that the theoretical perspective developed above provides a causal argument. The problems inherent to such a neopositivist epistemology to international politics (see Young, 1992: 163, footnote) are well known, and interpretive questions, such as how far partnering in turn changes the ideas and self-conceptions of the involved actors over time, are an important field to explore in the future. With regard to the empirical examination provided in this paper, it is necessary to point out its preliminary nature: in the future, a deeper and broader analysis is required to sustain the propositions made above. The analysis needs to go deeper in the sense that measures of ownership, reduced in this study to voting rights in governing boards, should take into account more aspects, such as the influence of host organizations or informal networks. It would also be useful to deepen the analysis of partnership outcomes at different stages of the R\&D process and corresponding implications for governance structures (e.g. basic research as a big public good component, as it generates knowledge, while late R\&D stage development is more 
product-specific and so has a larger private good component). Furthermore, the analysis needs to be broadened: it should be applied to a larger number of the more than 400 global partnerships existing today in various policy areas.

\section{References}

Besley, Timothy and Maitreesh Ghatak (2001), 'Government versus private ownership of public goods', Quarterly Journal of Economics, 116(4): 1343-1372.

Biersteker, Thomas J (1995), "The "triumph" of liberal economic ideas in the developing world', in B. Stallings (ed.), Global Change, Regional Response, The new International Context of Development.

Brundtland, Gro Harlem (2003), 'Global health and international security', Global Governance, 9: 417-423.

Buse, Kent (2004a), 'Global health partnerships, increasing their impact by improved governance', DFID Health Resource Center.

Buse, Kent (2004b), 'Governing public-private infectious disease partnerships', Brown Journal of World Affairs, 10(2): 225-242.

Buse, Kent and Amalia Waxman (2001), 'Public-private health partnerships: a strategy for the WHO', Bulletin of the World Health Organization, 79(8): 748-754.

Buse, Kent and Andrew Harmer (2004), 'Power to the partners? The politics of publicprivate health partnerships', Development, 47(2): 49-56.

Buse, Kent and Gill Walt (2000a), 'Global public-private partnerships: part I - a new development in health?', Bulletin of the World Health Organization, 78(4): 549-561.

Buse, Kent and Gill Walt (2000b), 'Global public-private partnerships: part II - what are the health issues for global governance?', Bulletin of the World Health Organization, 78(5): 699-709.

Buse, Kent and Gill Walt (2002a), 'Globalization and multilateral public-private health partnerships: issues for health policy', in K. Lee, K. Buse, and S. Fustukian (eds), Health Policy in a Globalizing World, Cambridge: Cambridge University Press.

Buse, Kent and Gill Walt (2002b), 'The World Health Organization and global publicprivate health partnerships: in search of "good" global health governance', in M. R. Reich (ed.), Public-Private Partnerships for Public Health, Boston: Harvard University Press.

Coase, Ronald (1937), 'The Nature of the Firm', Economica, 4.

Economist (2006), The Birth of Philanthrocapitalism, Economist print edition, 23 February.

Grossman, Sanford J. and Oliver D. Hart (1986), 'The costs and benefits of ownership: a theory of vertical and lateral integration', The Journal of Political Economy, 94(4): 691-719.

Hart, Oliver, Andrei Shleifer, and Robert Vishny (1997), 'The proper scope of government: theory and application to prisons', Quarterly Journal of Economics, 112(4): 1127-1161.

Hart, Oliver and John Moore (1990), 'Property rights and the nature of the firm', The Journal of Political Economy, 98(6): 1119-1158.

Hirschman, Alberto O. (1970), Exit, Voice, and Loyalty, Responses to Decline in Firms, Organizations, and States, Cambridge, MA: Harvard University Press. 
Jayasuriya, Kanishka (2001), 'Governance, post Washington consensus and the new anti politics', Southeast Asia Research Centre Working Paper Series 2.

Kaul, Inge and Pedro Conceição (2006), 'Why revisit public finance today?', in I. Kaul and P. Conceição (eds), The New Public Finance, Responding to Global Challenges, Oxford University Press.

Kaul, Inge, Pedro Conceição, Katell Le Goulven, and Ronald U. Mendoza (eds) (2003), Providing Global Public Goods. Managing Globalization, Oxford: Oxford University Press.

Kettler, Hannah and Adrian Towse (2001), 'Public-private partnerships: a report for the WHO Macroeconomic Commission on Health', CMH Working Paper Series Paper No. WG2: 21.

Kickbusch, Ilona and Kent Buse (2006), 'Global influences and global responses: international health at the turn of the twenty-first century', in M. H. Merson, R. E. Black and A. J. Mills (eds), International Public Health: Diseases, Programs, Systems, and Policies, Mississauga, Canada: Jones \& Bartlett Publishers International.

Moran, Mary (2005a), 'A breakthrough in R\&D for neglected diseases: new ways to get the drug we need', PLoS Medicine, 2(9).

Moran, Mary (2005b), The New Landscape of Neglected Disease Drug Development, The Wellcome Trust.

Nwaka, Solomon and Robert G. Ridley (2003), 'Virtual drug discovery and development for neglected diseases through public-private partnerships', Nature Reviews. Drug Discovery, 2.

Tarabusi, Claudio Casadio and Graham Vickery (1998a), 'Globalization in the pharmaceutical industry: part I', International Journal of Health Services, 2(1): 67-105.

Tarabusi, Claudio Casadio and Graham Vickery (1998b), 'Globalization in the pharmaceutical industry: part II', Journal of International Health Services, 28(2): 281-303.

Widdus, Roy (2001), 'Public-private partnerships for health: their main targets, their diversity, and their future directions', Bulletin of the World Health Organization, 79: 713-720.

Woods, Ngaire (1999), 'Good governance in international institutions', Global Governance, 5: 39-61.

WHO, Constitution of the World Health Organization, www.who.int.

Young, Oran R. (1992), 'The effectiveness of international institutions: hard cases and critical variables', in J. N. Rosenau and E.-O. Czempiel (eds), Governance without Government: Order and Change in World Politics, Cambridge: Cambridge University Press. 